\title{
Effects of GSTP1 and GPX1 Polymorphisms on the Risk of Preeclampsia in Chinese Han Women
}

\author{
Huijie Gao ${ }^{a, b, c}$ Chao Liu ${ }^{b}$ Ping Lin ${ }^{d}$ Luo Xu ${ }^{c}$ Xiao Lib Yujie Chen ${ }^{b}$ Baohua Cheng ${ }^{\mathrm{e}}$ \\ Aiqin $\mathrm{Li}^{f}$ Shiguo Liu ${ }^{\mathrm{a}}$
}

aPrenatal Diagnosis Center, the Affiliated Hospital of Qingdao University, Qingdao; ${ }^{b}$ Department of Basic Medicine, College of Pharmacy, Jining Medical University, Rizhao; 'Department of Pathophysiology, Medical College of Qingdao University; 'Department of Obstetrics and Gynaecology, the Affiliated Hospital of Qingdao University, Qingdao; 'Department of Human Anatomy, Foundation College of Jining Medical University, Jining; 'Outpatient Department, the Affiliated Hospital of Qingdao University, Qingdao, China

\section{Key Words}

Preeclampsia • GSTP1 • GPX1 • Polymorphism • Chinese

\begin{abstract}
Background/Aims: Increasing evidence shows that oxidative stress plays an important part in the pathophysiological mechanisms of preeclampsia (PE). Polymorphic variants of oxidative stress-related candidate genes GST1 and GPX1 can affect the antioxidant activities of their encoded enzymes. Therefore, this study aimed to explore the associational analysis between GSTP1 and GPX1 single nucleotide polymorphisms (SNPs) and susceptibility to PE in Chinese Han women. Methods: DNA from 1130 PE patients and 1226 healthy individuals was genotyped for SNPs rs1695 in GSTP1 and rs1050450 in GPX1 using a predesigned TaqMan SNP genotyping assay. The $\chi^{2}$ test compared differences in genetic distributions between the two groups in a case-control study. Results: No significant differences in allelic or genotypic frequencies of GSTP1 rs1695 or GPX1 rs1050450 were detected between cases and controls (GSTP1 rs1695: $\chi^{2}=1.122, p=0.571$ by genotype, $\chi^{2}=0.138, p=0.710$, odds ratio $=1.027,95 \%$ confidence interval $0.892-1.183$ by allele; GPX1 rs1050450: $\chi^{2}=0.036, p=0.982$ by genotype, $\chi^{2}=0.002, p=0.960$, odds ratio $=1.005,95 \%$ confidence interval $0.822-1.229$ by allele). Moreover, no significant differences in genetic distribution were found between early/late-onset PE or mild/severe PE and control subgroups. Conclusion: Our results suggest that GSTP1 rs1695 and GPX1 rs1050450 SNPs have no effects on the risk of PE in the Chinese Han population. However, these results should be confirmed by replication in different populations.
\end{abstract}




\section{Cellular Physiology Cell Physiol Biochem 2016;39:2025-2032

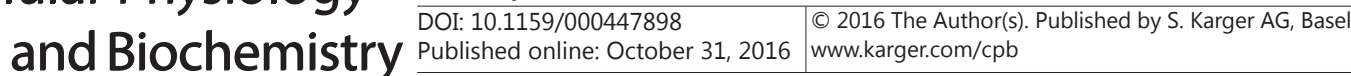 \\ Gao et al.: GSTP1 and GPX1 Variants and Preeclampsia in Chinese Han Women}

\section{Introduction}

Preeclampsia (PE) is a dangerous gestation-specific clinical syndrome characterized by new-onset hypertension and proteinuria that develops after the 20th week of gestation [1$3]$. It affects approximately $2 \%-10 \%$ of all pregnant women worldwide, and is one of the leading causes of maternal and perinatal mortality and morbidity, especially in developing countries $[4,5]$. Increasing evidence has shown that endothelial cell dysfunction and damage play an important role in the pathophysiological mechanisms of PE [2, 6-8].

During normal gestation, reactive oxygen species (ROS) generation is increased with the increase of oxygen levels resulting from established maternal intraplacental circulation at the end of the first trimester $[9,10]$. The placenta must adapt to this increased ROS level to enable normal fetal development $[11,12]$. However, increased ROS exposure can also result in lipid peroxidation, protein carboxylation, and DNA oxidation, leading to the intravascular inflammatory responses and endothelial cell dysfunction observed in PE patients $[10,13]$. Normally, the effect of ROS can be counterbalanced by that of antioxidants such as glutathione, vitamins $\mathrm{C}$ and $\mathrm{E}$, and some enzymes, including glutathione peroxidases (GPxs), glutathione S-transferases (GSTs), and superoxide dismutase $[14,15]$. When this balance between the formation of ROS and intrinsic antioxidant defense mechanisms is upset, oxidative stress arises, which is thought to be behind the pathophysiological mechanisms of PE $[16,17]$.

GSTs can detoxify multiple hazardous substances, such as ROS, by catalyzing the conjugation of the reduced form of glutathione (GSH) to xenobiotic substrates for the purpose of detoxification [18]. GSTs are encoded by the GST family of genes located on different chromosomes, and can be classified into three groups: cytosolic, mitochondrial, and microsomal [19]. GSTP1 encodes one of the four known main classes of cytosolic GSTs, and is located on human chromosome 11q13. Its single nucleotide polymorphism (SNP) within exon 5, Ile105Val (rs1695), leads to the exchange of valine and isoleucine which results in decreased enzymatic activity of the protein [20,21].

GPxs can reduce free hydrogen peroxide to water using GSH as an obligate cosubstrate to protect the organism from oxidative damage [22]. GPxs are encoded by the GPX phylogenetically related family of genes located on different chromosomes. Human GPX-1 is located on human chromosome 3p21, and has a common SNP (rs1050450) involving the substitution of leucine for proline at amino acid 198 resulting from a $\mathrm{C} \rightarrow \mathrm{T}$ change. Many studies have suggested that this SNP affects GPx-1 activity [23, 24].

Because polymorphic variants of GST and GPX can affect the antioxidant activities of the enzymes they encode, we hypothesized that polymorphic loci might contribute to individual differences in susceptibility to PE. Therefore, we estimated the effects of GPX1 rs1050450 and GSTP1 rs1695 on the risk of PE in a sample of 2356 women living in China with the aim of identifying potential prognostic or predictive tools for women at risk of PE.

\section{Materials and Methods}

\section{Subjects}

This case-control study enrolled $1130 \mathrm{PE}$ patients and 1226 control subjects recruited from the Affiliated Hospital of QingDao University, Linyi People's Hospital, Liaocheng People's Hospital, and Zaozhuang Municipal Hospital between January 2013 and November 2015. All patients provided their informed written consent and the study was approved by the Ethical Committees of the Affiliated Hospital of Qingdao University in accordance with the Code of Ethics of the Declaration of Helsinki.

The following data on each subject were recorded: age, body height, body weight, age of menarche, systolic and diastolic blood pressure, and gestational age (at admission and at delivery). All pregnant women underwent serum and urine specimen analysis before labor.

The diagnostic basis for PE was new-onset hypertension ( $\geq 140 / 90 \mathrm{mmHg}$ ) and proteinuria ( $\geq 0.3 \mathrm{~g} / 24$ $\mathrm{h}$, or $\geq 1+$ by dipstick) that developed after the 20 th week of gestation [25]. Some accompanying symptoms were permitted as part of the diagnosis, including upper abdominal discomfort, headache, and blurred 


\section{Cellular Physiology Cell Physiol Biochem 2016;39:2025-2032

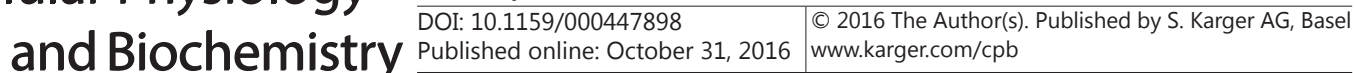 \\ Gao et al.: GSTP1 and GPX1 Variants and Preeclampsia in Chinese Han Women}

vision. Based on guidelines from the American College of Obstetricians and Gynecologists [26], PE patients were divided into mild and severe groups. Because early-onset PE patients are more severely affected than those with late-onset PE $[27,28]$, patients in this study were also divided into an early-onset PE subgroup diagnosed before the 34th week of gestation, and a late-onset PE subgroup diagnosed at or after the 34th week of gestation. No individuals with PE had a previous history of PE or systemic diseases such as chronic hypertension, heart disease, diabetes mellitus, thyroid function disorder, kidney disorders, hepatic diseases, blood transfusion, or immunotherapy.

Inclusion criteria for controls were as follows: 1 ) age $\geq 26$ years; 2) gestational age at admission $\geq 30$ weeks; 3) no previous history of PE or systemic diseases such as chronic hypertension, heart disease, diabetes mellitus, thyroid function disorder, kidney disorders, hepatic diseases, blood transfusion, or immunotherapy; and 4) no obstetric complications. All controls were followed up and none of them developed PE at the end of pregnancy or after birth.

Genetic studies

Genomic DNA was isolated from peripheral venous blood using standard methods. Genotyping for SNPs GSTP1 rs1695 and GPX1 rs1050450 was conducted with TaqMan assays (Applied Biosystems, Waltham, MA) using the CFX96 real-time PCR detection system. TaqMan probes and primers were synthesized by Applied Biosystems of Life Technologies (New York, NY). GSTP1 and GPX1 were amplified using the following primers: 5'-GAT GCT CAC ATA GTT GGT GTA G-3' and 5'-GGT GGA CAT GGT GAA TGA C-3' for GSTP1 and 5'-GCTTCCAGACCATTGA CATC-3' and 5'-CGA GGT GGT ATT TTC TGT AAG ATC-3' for GPX1. PCR was carried out in a final volume of $25 \mu \mathrm{l}$ containing $1.25 \mu \mathrm{l} 20 \times$ SNP genotyping assay, $12.5 \mu \mathrm{l}$ $2 \times$ PCR MasterMix, and $11.25 \mu \mathrm{l}$ DNA and DNase-free water. Amplifications were carried out in a C1000 ${ }^{\mathrm{TM}}$ thermal cycler and CFX96 ${ }^{\mathrm{TM}}$ real-time system (Bio-Rad, Hercules, CA) under the following conditions: initial denaturation at $94^{\circ} \mathrm{C}$ for $4 \mathrm{~min}$, followed by 45 cycles of $94^{\circ} \mathrm{C}$ for $15 \mathrm{~s}$ and $66^{\circ} \mathrm{C}$ for $1 \mathrm{~min}$. We detected fluorescent signals from VIC/FAM-labeled probes in each cycle. Genotype analysis was conducted using BioRad CFX manager 3.0 software.

\section{Statistical analysis}

All data analyses in this study were performed using the Statistical Package for Social Sciences (Version 12.0 for Windows; SPSS Inc., Chicago, IL). The homogeneity $\chi^{2}$ test was used to test the HardyWeinberg equilibrium (HWE) of the genotype distribution. Differences in genotypic and allelic frequencies of rs1695 and rs 1050450 between cases and controls were compared by the $\chi^{2}$ test. $p<0.05$ was considered to denote statistical significance. Odds ratios (ORs) and 95\% confidence intervals (CIs) were used to show the degree of relative risk. The analysis of power was performed using the program Power and Sample Size Calculations (PS, Version 3.1.2), considering an alpha of 0.05.

\section{Results}

\section{Demographic and clinical characteristics}

Demographic and clinical characteristics of cases and controls are shown in Table 1. We found no significant differences for maternal age, gravidity, number of abortions, or age of menarche between cases and controls (all $\mathrm{p}>0.05$ ). However, significant differences in gestational weeks, fetal birth weights, blood pressure, white blood cells, and neutrophils were observed between the two groups (all $\mathrm{p}<0.05$ ).

\section{Genotypic and allelic frequencies}

The allelic and genotypic distribution of GSTP1 rs1695 and GPX1 rs1050450 showed that the samples in our study conform to HWE. Table 2 shows that there were no significant differences in allelic or genotypic frequencies of GSTP1 rs1695 or GPX1 rs1050450 between PE patients and controls (rs1695: $\chi^{2}=1.122, p=0.571$ by genotype, $\chi^{2}=0.138, p=0.710$, OR=1.027, 95\%CI $0.892-1.183$ by allele; rs1050450: $\chi^{2}=0.036, p=0.982$ by genotype, $\chi^{2}=0.002, p=0.960, \mathrm{OR}=1.005,95 \%$ CI $0.822-1.229$ by allele). 
Table 1. The demographic and clinical characteristics of PE and control groups

\begin{tabular}{lcccc}
\hline Characteristics & $\mathrm{PE}(\mathrm{N}=1130)$ & Control $(\mathrm{N}=1226)$ & $\mathrm{t}$ & $p$-value \\
\hline Maternal age(years) & $30.07 \pm 5.67$ & $30.30 \pm 4.11$ & -1.109 & 0.268 \\
Times of gravidity & $2.25 \pm 1.29$ & $2.25 \pm 1.19$ & -0.027 & 0.979 \\
Number of abortion & $0.65 \pm 0.96$ & $0.64 \pm 0.86$ & 0.148 & 0.882 \\
Age of menarche(years) & $14.04 \pm 1.24$ & $14.09 \pm 1.27$ & -0.974 & 0.330 \\
Gestational age at admission (weeks) & $35.53 \pm 3.61$ & $39.06 \pm 1.54$ & -29.764 & $<0.001$ \\
Gestational age at delivery(weeks) & $36.28 \pm 3.14$ & $39.35 \pm 1.30$ & -29.051 & $<0.001$ \\
Fetal birth weight $(\mathrm{kg})$ & $2.61 \pm 0.94$ & $3.41 \pm 0.37$ & -25.259 & $<0.001$ \\
Systolic blood pressure $(\mathrm{mmHg})$ & $159.31 \pm 19.05$ & $114.28 \pm 10.38$ & 70.067 & $<0.001$ \\
Diastolic blood pressure $(\mathrm{mmHg})$ & $104.03 \pm 13.69$ & $73.37 \pm 7.84$ & 65.635 & $<0.001$ \\
White blood cell $\left(\times 10^{9} / \mathrm{L}\right)$ & $9.66 \pm 3.56$ & $9.02 \pm 2.62$ & 4.901 & $<0.001$ \\
Neutrophil $\left(\times 10^{9} / \mathrm{L}\right)$ & $7.19 \pm 2.819$ & $6.93 \pm 2.48$ & 2.305 & 0.021 \\
\hline
\end{tabular}

Table 2. The comparison of genotypic and allelic frequencies between PE and control groups

\begin{tabular}{|c|c|c|c|c|c|c|c|c|c|}
\hline \multirow[b]{2}{*}{ SNP } & \multicolumn{5}{|c|}{ Allelic test } & \multicolumn{3}{|c|}{ Genotypic test } & \multirow[b]{2}{*}{$\chi^{2}$} \\
\hline & Allele & $\mathrm{PE} /$ control & $p$ & $\chi^{2}$ & OR(95\% CI) & Genotype & $\mathrm{PE} /$ control & $p$ & \\
\hline \multirow{5}{*}{ rs1695 } & A & $1798 / 1940$ & & & & $\mathrm{AA}$ & $705 / 764$ & & \\
\hline & G & $462 / 512$ & 0.710 & 0.138 & $1.027 \quad(0.892-1.183)$ & $\mathrm{AG}$ & $388 / 412$ & 0.571 & 1.122 \\
\hline & & & & & & GG & $37 / 50$ & & \\
\hline & $\mathrm{C}$ & $2060 / 2234$ & & & & $\mathrm{CC}$ & $942 / 1022$ & & \\
\hline & $\mathrm{T}$ & $200 / 218$ & 0.960 & 0.002 & $1.005 \quad(0.822-1.229)$ & CT & $176 / 190$ & 0.982 & 0.036 \\
\hline rs1050450 & & & & & & TT & $12 / 14$ & & \\
\hline
\end{tabular}

Table 3. Analysis of the three SNPs based on three genetic models

\begin{tabular}{|c|c|c|c|c|c|c|c|c|}
\hline \multirow{2}{*}{ SNP } & \multirow{2}{*}{ Genotype } & \multirow{2}{*}{$\mathrm{PE} /$ control } & \multicolumn{2}{|c|}{ Additive model } & \multicolumn{2}{|c|}{ Dominant model } & \multicolumn{2}{|c|}{ Recessive model } \\
\hline & & & $p$ & OR(95\% CI) & $p$ & OR(95\% CI) & $p$ & OR(95\% CI) \\
\hline \multirow{3}{*}{ rs1695 } & $\mathrm{AA}$ & $705 / 764$ & \multirow{3}{*}{0.32} & \multirow{3}{*}{$\begin{array}{c}0.80 \\
(0.52-1.24)\end{array}$} & \multirow{3}{*}{0.97} & \multirow{3}{*}{$\begin{array}{c}0.99 \\
(0.84-1.18)\end{array}$} & \multirow{3}{*}{0.30} & \multirow{3}{*}{$\begin{array}{c}0.79 \\
(0.52-1.23)\end{array}$} \\
\hline & $\mathrm{AG}$ & $388 / 412$ & & & & & & \\
\hline & GG & $37 / 50$ & & & & & & \\
\hline \multirow{3}{*}{ rs1050450 } & $\mathrm{CC}$ & $942 / 1022$ & \multirow{3}{*}{0.85} & \multirow{3}{*}{$\begin{array}{c}0.93 \\
(0.43-2.02)\end{array}$} & \multirow{3}{*}{0.99} & \multirow{3}{*}{$\begin{array}{c}1.00 \\
(0.81-1.24)\end{array}$} & \multirow{3}{*}{0.85} & \multirow{3}{*}{$\begin{array}{c}0.93 \\
(0.43-2.02)\end{array}$} \\
\hline & $\mathrm{CT}$ & $176 / 190$ & & & & & & \\
\hline & TT & $12 / 14$ & & & & & & \\
\hline
\end{tabular}

Table 4. The comparison of genetic distributions between mild/severe PE and control groups

\begin{tabular}{|c|c|c|c|c|c|c|c|c|c|}
\hline \multirow{2}{*}{ SNP } & \multicolumn{5}{|c|}{ Allelic test } & \multicolumn{4}{|c|}{ Genotypic test } \\
\hline & Allele & PE/control & $p$ & $\chi^{2}$ & $\mathrm{OR}(95 \% \mathrm{CI})$ & Genotype & PE/control & $p$ & $\chi^{2}$ \\
\hline \multirow{3}{*}{$\begin{array}{l}\text { rs1695 (mild } \\
\mathrm{PE} / \text { control) }\end{array}$} & $\mathrm{A}$ & $389 / 1940$ & \multirow{3}{*}{0.341} & \multirow{3}{*}{0.908} & \multirow{3}{*}{$\begin{array}{c}1.128 \\
(0.880-1.446)\end{array}$} & $\mathrm{AA}$ & $156 / 764$ & \multirow{3}{*}{0.587} & \multirow{3}{*}{1.066} \\
\hline & \multirow[t]{2}{*}{ G } & \multirow[t]{2}{*}{$91 / 512$} & & & & $A G$ & $77 / 412$ & & \\
\hline & & & & & & GG & $7 / 50$ & & \\
\hline rs1695 & A & $1409 / 1940$ & \multirow{3}{*}{0.976} & \multirow{3}{*}{0.001} & \multirow{3}{*}{$\begin{array}{c}1.002 \\
(0.863-1.165)\end{array}$} & $\mathrm{AA}$ & $549 / 764$ & \multirow{3}{*}{0.611} & \multirow{3}{*}{0.986} \\
\hline (severe & \multirow[t]{2}{*}{ G } & \multirow[t]{2}{*}{$371 / 512$} & & & & AG & $311 / 412$ & & \\
\hline PE/control) & & & & & & GG & $30 / 50$ & & \\
\hline rs1050450 & $\mathrm{C}$ & $437 / 2234$ & \multirow{3}{*}{0.962} & \multirow{3}{*}{0.002} & \multirow{3}{*}{$\begin{array}{c}0.992 \\
(0.704-1.397)\end{array}$} & $\mathrm{CC}$ & $202 / 1022$ & \multirow{3}{*}{0.408} & \multirow{3}{*}{1.791} \\
\hline (mild & \multirow[t]{2}{*}{$\mathrm{T}$} & \multirow[t]{2}{*}{$43 / 218$} & & & & CT & $33 / 190$ & & \\
\hline PE/control) & & & & & & TT & $5 / 14$ & & \\
\hline rs1050450 & C & $1623 / 2234$ & \multirow{3}{*}{0.937} & \multirow{3}{*}{0.006} & \multirow{3}{*}{$\begin{array}{c}1.009 \\
(0.814-1.251)\end{array}$} & $\mathrm{CC}$ & $740 / 1022$ & \multirow{3}{*}{0.682} & \multirow{3}{*}{0.766} \\
\hline (severe & $\mathrm{T}$ & $157 / 218$ & & & & CT & $143 / 190$ & & \\
\hline $\mathrm{PE} /$ control) & & & & & & TT & $7 / 14$ & & \\
\hline
\end{tabular}

Various models of inheritance were used to ensure sufficient statistical power for the detection of disease susceptibility loci. Therefore, genotype frequencies were further analyzed by additive, dominant, and recessive genetic models, and rs1050450 and rs1695 were found not to be risk factors for PE based on these models (all p >0.05) (Table 3). 


\section{Cellular Physiology Cell Physiol Biochem 2016;39:2025-2032 \begin{tabular}{ll|l} 
DOI: 10.1159/000447898 & $\begin{array}{l}\text { O 2016 The Author(s). Published by S. Karger AG, Basel } \\
\text { wwww.karger.com/cpb }\end{array}$
\end{tabular} \\ Gao et al.: GSTP1 and GPX1 Variants and Preeclampsia in Chinese Han Women}

Table 5. The comparison of genetic distributions between early/late-onset PE and control groups

\begin{tabular}{|c|c|c|c|c|c|c|c|c|c|}
\hline \multirow{2}{*}{ SNP } & \multicolumn{5}{|c|}{ Allelic test } & \multicolumn{4}{|c|}{ Genotypic test } \\
\hline & Allele & $\mathrm{PE} /$ control & $p$ & $\chi^{2}$ & OR(95\% CI) & Genotype & $\mathrm{PE} /$ control & $p$ & $\chi^{2}$ \\
\hline \multirow{3}{*}{$\begin{array}{l}\text { rs } 1695 \\
\text { (Early-onset } \\
\text { PE/control) }\end{array}$} & A & $517 / 1940$ & \multirow{3}{*}{0.611} & \multirow{3}{*}{0.259} & \multirow{3}{*}{$\begin{array}{c}1.058 \\
(0.852-1.313)\end{array}$} & $\mathrm{AA}$ & $207 / 764$ & \multirow{3}{*}{0.837} & \multirow{3}{*}{0.356} \\
\hline & \multirow[t]{2}{*}{ G } & \multirow[t]{2}{*}{$129 / 512$} & & & & $\mathrm{AG}$ & $103 / 412$ & & \\
\hline & & & & & & GG & $13 / 50$ & & \\
\hline rs1695 & A & $1217 / 1940$ & \multirow{3}{*}{0.994} & \multirow{3}{*}{$\begin{array}{c}< \\
0.001\end{array}$} & \multirow{3}{*}{$\begin{array}{c}1.001 \\
(0.855-1.171)\end{array}$} & $\mathrm{AA}$ & $472 / 764$ & \multirow{3}{*}{0.421} & \multirow{3}{*}{1.729} \\
\hline (Late-onset & \multirow[t]{2}{*}{ G } & \multirow{2}{*}{$321 / 512$} & & & & $A G$ & $273 / 412$ & & \\
\hline PE/control) & & & & & & GG & $24 / 50$ & & \\
\hline rs1050450 & C & $589 / 2234$ & \multirow{3}{*}{0.957} & \multirow{3}{*}{0.003} & \multirow{3}{*}{$\begin{array}{c}1.008 \\
(0.743-1.368)\end{array}$} & $\mathrm{CC}$ & $271 / 1022$ & \multirow{3}{*}{0.778} & \multirow{3}{*}{0.502} \\
\hline (Early-onset & \multirow[t]{2}{*}{$\mathrm{T}$} & \multirow[t]{2}{*}{$57 / 218$} & & & & $\mathrm{CT}$ & $47 / 190$ & & \\
\hline PE/control) & & & & & & $\mathrm{TT}$ & $5 / 14$ & & \\
\hline rs1050450 & C & $1402 / 2234$ & \multirow{3}{*}{0.959} & \multirow{3}{*}{0.003} & \multirow{3}{*}{$\begin{array}{c}1.006 \\
(0.804-1.259)\end{array}$} & $\mathrm{CC}$ & $639 / 1022$ & \multirow{3}{*}{0.691} & \multirow{3}{*}{0.739} \\
\hline (Late-onset & $\mathrm{T}$ & $136 / 218$ & & & & $\mathrm{CT}$ & $124 / 190$ & & \\
\hline $\mathrm{PE} /$ control) & & & & & & TT & $6 / 14$ & & \\
\hline
\end{tabular}

Table 4 shows that there were also no significant differences in genotypic or allelic frequencies of rs1695 or rs1050450 between mild/severe PE patients and controls. Similarly, Table 5 lists no significant differences in allelic and genotypic frequencies of rs1695 or rs1050450 between early/late-onset PE and control groups.

\section{Discussion}

The etiology and pathogenesis of PE are not completely understood [29-33], and there are currently no prognostic or predictive tools available for women at risk of PE. However, multiple pieces of evidence illustrate that oxidative stress plays an important role in PE pathophysiological mechanisms $[16,17,34]$.

Glutathione can neutralize free radicals and ROS in an antioxidation process that is dependent on the activities of antioxidant enzymes such as GPxs and GSTs. When the antioxidant activity of GPxs and GSTs in pregnant women is overwhelmed by the formation of ROS, oxidative stress is more likely to arise.

Cytosolic GSTs can be subdivided into four major classes: alpha, mu, pi, and theta [19]. In recent years, polymorphisms of GSTT1, GSTM1, and GSTP1 have been reported to associate with many pathologies including various cancers and diabetes, as well as PE [3540]. We were intrigued by the role of GSTP1 in PE. The substitution of G for A at nucleotide 313 of GSTP1 leads to an isoleucine-to-valine change at position 105 (I105V), resulting in decreased enzyme catalytic activity.

In a previous study, Zusterzeel found that $36 \%$ of 170 PE white Dutch women with a history of PE carried one rare Val105 allele while 14\% carried two Val105 alleles, compared with $41 \%$ and $5 \%$, respectively, in controls. This suggested that women with the GSTP1 P1b1 b genotype have a higher susceptibility to PE [41, 42]. Similarly, in a Japanese study, 26\% of 97 patients with PE from Hokkaido University Hospital carried one Val105 allele while $74 \%$ lacked the Val105 allele, indicating that the Val105 allele is associated with PE risk [43]. However, this is not supported by other studies [44-46]. For example, Maya-Mestizo women with PE from Mexico had an AG genotype frequency of $44.8 \%$ and a GG genotype frequency of $20 \%$ for the GSTP1 $313 \mathrm{G}$ allele compared with $54.7 \%$ and $24.4 \%$, respectively, in controls, suggesting that both genotypes conferred a reduced risk of PE [46]. Another study by these authors of women from the same ethnicity investigated the GSTP1 polymorphism rs 1695. This reported an AG genotype frequency of $47.39 \%$ and a GG genotype frequency of $35.66 \%$ for women with PE, compared with $47.16 \%$ and $32.95 \%$, respectively, in controls, indicating that there is no association between this GSTP1 polymorphism and PE in this population [44]. 
Because of the different viewpoints, it is necessary to test several factors, such as sample size and population, in the analysis of a GSTP1 association with PE. For this reason, we analyzed more than 2000 Chinese Han women in the present study. We observed AA, AG, and GG genotype frequencies in women with PE of $62.39 \%, 34.34 \%$, and $3.27 \%$, respectively. Although AG and GG genotype frequencies in the East Asian population (Chinese and Japanese individuals) are lower than those of other populations, we found no significant differences in allelic or genotypic frequencies of GSTP1 rs1695 between PE patients and controls in our study. To further understand the relationship between GSTP1 rs1695 and PE, we compared allelic and genotypic frequencies between early/late-onset PE or mild/severe PE and control groups, but again observed no significant differences. Consequently, the GSTP1 rs1695 SNP does not appear to be associated with susceptibility to PE in the Chinese Han population, so is not a suitable predictive tool for Chinese women at risk of PE.

The GPx family of antioxidant enzymes consists of eight groups, GPx1-8 [47, 48]. GPx-1 is present in all cells and is a crucial antioxidant enzyme that is more effective than catalase at removing intracellular peroxides under many physiological conditions [22]. Multiple GPX-1 SNPs have been reported, with rs 1050450 being one of the most common, and several studies have associated them with different pathologies. For instance, Hu et al. demonstrated that breast cancer risk was associated with $G P x-1$ rs1050450, and reported a higher frequency of the Leu/Leu genotype in breast cancer tissues [49]. Tang et al. also observed a significant association between the T allele of $G P x-1$ rs1050450 and peripheral neuropathy in diabetics [50]. In this study, we compared allelic and genotypic frequencies of rs 1050450 between $1130 \mathrm{PE}$ patients and 1226 controls, as well as between early/late-onset PE or mild/severe $\mathrm{PE}$ and control groups, but found no significant differences.

In conclusion, this is the first study to investigate the association between GSTP1 and GPx1 SNPs with PE in a Chinese population. Our findings suggest that SNPs rs1695 and rs1050450 are not associated with susceptibility to PE in the Chinese Han population. Moreover, because our post-hoc power calculations for rs1695 and rs1050450 are $6.6 \%$ and $5.0 \%$ respectively, our results are likely to be credible given the sufficient sample size of our study. However, regional and racial differences are likely to affect the results, and because most subjects in our study were Chinese Han from Shandong Province, larger-scale studies from different regions are necessary to validate our findings.

\section{Acknowledgements}

We are grateful to all participants of this study. This work was supported by the National Natural Science Foundation of China (81371499 and 30971586) and Projects of Medical and Health Technology Development Program of Shandong Province (2015WSB33012 and 2015WS0420).

\section{Disclosure Statement}

The authors declare that no competing interests exist. The manuscript has been read and approved by all named authors.

\section{References}

1 Walker JJ: Pre-eclampsia. Lancet 2000;356:1260-1265.

2 Redman CW, Sargent IL: Latest advances in understanding preeclampsia. Science 2005;308:1592-1594.

3 North RA, McCowan LM, Dekker GA, Poston L, Chan EH, Stewart AW, Black MA, Taylor RS, Walker JJ, Baker PN, Kenny LC: Clinical risk prediction for pre-eclampsia in nulliparous women: Development of model in international prospective cohort. BMJ 2011;342:d1875.

4 Lain KY, Roberts JM: Contemporary concepts of the pathogenesis and management of preeclampsia. JAMA 2002;287:3183-3186. 


\section{Cellular Physiology Cell Physiol Biochem 2016;39:2025-2032 \begin{tabular}{l|l|l|l|}
\hline DOI: 10.1159/000447898 2016 The Author(s). Published by S. Karger AG, Basel & (c)
\end{tabular} and BiOchemistry Published online: October 31, 2016 www.karger.com/cpb \\ Gao et al.: GSTP1 and GPX1 Variants and Preeclampsia in Chinese Han Women}

5 Berg CJ, Mackay AP, Qin C, Callaghan WM: Overview of maternal morbidity during hospitalization for labor and delivery in the united states: 1993-1997 and 2001-2005. Obstet Gynecol 2009;113:1075-1081.

6 Lam C, Lim KH, Karumanchi SA: Circulating angiogenic factors in the pathogenesis and prediction of preeclampsia. Hypertension 2005;46:1077-1085.

$7 \quad$ Myatt L, Webster RP: Vascular biology of preeclampsia. J Thromb Haemost 2009; 7:375-384.

8 Shen Z, Wu Y, Chen X, Chang X, Zhou Q, Zhou J, Ying H, Zheng J, Duan T, Wang K: Decreased maternal serum 2-methoxyestradiol levels are associated with the development of preeclampsia. Cell Physiol Biochem 2014;34:2189-2199.

9 Myatt L, Cui X: Oxidative stress in the placenta. Histochem Cell Biol 2004;122:369-382.

10 Burton GJ, Jauniaux E: Oxidative stress. Best Pract Res Clin Obstet Gynaecol 2011;25:287-299.

11 Poston L, Raijmakers MT: Trophoblast oxidative stress, antioxidants and pregnancy outcome--a review. Placenta 2004;25 Suppl A:S72-78.

12 Tuuli MG, Longtine MS, Nelson DM: Review: Oxygen and trophoblast biology--a source of controversy. Placenta 2011;32 Suppl 2:S109-118.

13 Myatt L: Review: Reactive oxygen and nitrogen species and functional adaptation of the placenta. Placenta 2010;31 Suppl:S66-69.

14 Poranen AK, Ekblad U, Uotila P, Ahotupa M: Lipid peroxidation and antioxidants in normal and preeclamptic pregnancies. Placenta 1996;17:401-405.

15 Seidegard J, Ekstrom G: The role of human glutathione transferases and epoxide hydrolases in the metabolism of xenobiotics. Environ Health Perspect 1997;105 Suppl 4:791-799.

16 Chaiworapongsa T, Chaemsaithong P, Yeo L, Romero R: Pre-eclampsia part 1: Current understanding of its pathophysiology. Nat Rev Nephrol 2014;10:466-480.

17 Sanchez-Aranguren LC, Prada CE, Riano-Medina CE, Lopez M: Endothelial dysfunction and preeclampsia: Role of oxidative stress. Front Physiol 2014;5:372.

18 Yang Y, Parsons KK, Chi L, Malakauskas SM, Le TH: Glutathione s-transferase-micro1 regulates vascular smooth muscle cell proliferation, migration, and oxidative stress. Hypertension 2009;54:1360-1368.

19 Hayes JD, Flanagan JU, Jowsey IR: Glutathione transferases. Annu Rev Pharmacol Toxicol 2005;45:51-88.

20 Watson MA, Stewart RK, Smith GB, Massey TE, Bell DA: Human glutathione s-transferase p1 polymorphisms: Relationship to lung tissue enzyme activity and population frequency distribution. Carcinogenesis 1998;19:275-280.

21 Sundberg K, Johansson AS, Stenberg G, Widersten M, Seidel A, Mannervik B, Jernstrom B: Differences in the catalytic efficiencies of allelic variants of glutathione transferase p1-1 towards carcinogenic diol epoxides of polycyclic aromatic hydrocarbons. Carcinogenesis 1998;19:433-436.

22 Lubos E, Loscalzo J, Handy DE: Glutathione peroxidase-1 in health and disease: From molecular mechanisms to therapeutic opportunities. Antioxid Redox Signal 2011;15:1957-1997.

23 Hamanishi T, Furuta H, Kato H, Doi A, Tamai M, Shimomura H, Sakagashira S, Nishi M, Sasaki H, Sanke T, Nanjo K: Functional variants in the glutathione peroxidase-1 (gpx-1) gene are associated with increased intima-media thickness of carotid arteries and risk of macrovascular diseases in japanese type 2 diabetic patients. Diabetes 2004;53:2455-2460.

24 Cao M, Mu X, Jiang C, Yang G, Chen H, Xue W: Single-nucleotide polymorphisms of gpx1 and mnsod and susceptibility to bladder cancer: A systematic review and meta-analysis. Tumour Biol 2014;35:759-764.

25 Report of the national high blood pressure education program working group on high blood pressure in pregnancy. Am J Obstet Gynecol 2000;183:S1-S22.

26 Acog Committee on Obstetric Practice: ACOG practice bulletin. Diagnosis and management of preeclampsia and eclampsia. Number 33, january 2002. American college of obstetricians and gynecologists. Int J Gynaecol Obstet 2002;77:67-75.

27 Alvarez-Fernandez I, Prieto B, Rodriguez V, Ruano Y, Escudero AI, Alvarez FV: New biomarkers in diagnosis of early onset preeclampsia and imminent delivery prognosis. Clin Chem Lab Med 2014;52:1159-1168.

28 Li H, Han L, Yang Z, Huang W, Zhang X, Gu Y, Li Y, Liu X, Zhou L, Hu J, Yu M, Yang J, Li Y, Zheng Y, Guo J, Han J, Li L: Differential Proteomic Analysis of Syncytiotrophoblast Extracellular Vesicles from Early-Onset Severe Preeclampsia, using 8-Plex iTRAQ Labeling Coupled with 2D Nano LC-MS/MS. Cell Physiol Biochem 2015;36:1116-1130.

29 Chen A, Li C, Wang J, Sha H, Piao S, Liu S: Role of Toll-Like Receptor 3 Gene Polymorphisms in Preeclampsia. Cell Physiol Biochem 2015;37:1927-1933. 


\section{Cellular Physiology Cell Physiol Biochem 2016;39:2025-2032 \begin{tabular}{l|l|l|l|l|l}
\hline DOI: 10.1159/000447898 & $\begin{array}{l}\text { C) } 2016 \text { The Author(s). Published by S. Karger AG, Basel } \\
\text { www.karger.com/cpb }\end{array}$
\end{tabular} \\ Gao et al.: GSTP1 and GPX1 Variants and Preeclampsia in Chinese Han Women}

30 Jia R, Li J, Rui C, Ji H, Ding H, Lu Y, De W, Sun L: Comparative Proteomic Profile of the Human Umbilical Cord Blood Exosomes between Normal and Preeclampsia Pregnancies with High-Resolution Mass Spectrometry. Cell Physiol Biochem 2015;36:2299-2306.

31 Li J, Ying H, Cai G, Guo Q, Chen L: Pre-Eclampsia-Associated Reduction in Placental Growth Factor Impaired Beta Cell Proliferation Through PI3k Signalling. Cell Physiol Biochem 2015;36:34-43.

32 Liu L, Zhang X, Rong C, Rui C, Ji H, Qian YJ, Jia R, Sun L: Distinct DNA methylomes of human placentas between pre-eclampsia and gestational diabetes mellitus. Cell Physiol Biochem 2014;34:1877-1889.

33 Jia RZ, Ding GC, Gu CM, Huang T, Rui C, Wang YX, Lu Q: CDX2 enhances HTR-8/SVneo trophoblast cell invasion by altering the expression of matrix metalloproteinases. Cell Physiol Biochem 2014;34:628-636.

34 Huang QT, Chen JH, Hang LL, Liu SS, Zhong M: Activation of PAR-1/NADPH oxidase/ROS signaling pathways is crucial for the thrombin-induced sFlt-1 production in extravillous trophoblasts: possible involvement in the pathogenesis of preeclampsia. Cell Physiol Biochem 2015;35:1654-1662.

35 Gao LB, Pan XM, Li LJ, Liang WB, Bai P, Rao L, Su XW, Wang T, Zhou B, Wei YG, Zhang L: Null genotypes of gstm 1 and gstt1 contribute to risk of cervical neoplasia: An evidence-based meta-analysis. PloS One 2011;6:e20157.

36 Zhang ZJ, Hao K, Shi R, Zhao G, Jiang GX, Song Y, Xu X, Ma J: Glutathione s-transferase m1 (gstm1) and glutathione s-transferase $\mathrm{t} 1$ (gstt1) null polymorphisms, smoking, and their interaction in oral cancer: A huge review and meta-analysis. Am J Epidemiol 2011;173:847-857.

37 Song K, Yi J, Shen X, Cai Y: Genetic polymorphisms of glutathione s-transferase genes gstm1, gstt1 and risk of hepatocellular carcinoma. PloS One 2012;7:e48924.

38 Yu Y, Weng Y, Guo J, Chen G, Yao K: Association of glutathione s transferases polymorphisms with glaucoma: A meta-analysis. PloS One 2013;8:e54037.

39 Saadat M, Anvar Z, Namavar-Jahromi B, Saadat I: Genetic polymorphisms of glutathione s-transferase z1 (gstz1) and susceptibility to preeclampsia. Mol Biol Rep 2012;39:8995-8998.

40 Zhang J, Masciocchi M, Lewis D, Sun W, Liu A, Wang Y: Placental anti-oxidant gene polymorphisms, enzyme activity, and oxidative stress in preeclampsia. Placenta 2008;29:439-443.

41 Zusterzeel PL, Visser W, Peters WH, Merkus HW, Nelen WL, Steegers EA: Polymorphism in the glutathione s-transferase $\mathrm{p} 1$ gene and risk for preeclampsia. Obstet Gynecol 2000;96:50-54.

42 Zusterzeel PL, te Morsche R, Raijmakers MT, Roes EM, Peters WH, Steegers EA: Paternal contribution to the risk for pre-eclampsia. J Med Genet 2002;39:44-45.

43 Ohta K, Kobashi G, Hata A, Yamada H, Minakami H, Fujimoto S, Kondo K, Tamashiro H: Association between a variant of the glutathione s-transferase p1 gene (gstp1) and hypertension in pregnancy in japanese: Interaction with parity, age, and genetic factors. Semin Thromb Hemost 2003;29:653-659.

44 Coral-Vazquez RM, Romero Arauz JF, Canizales-Quinteros S, Coronel A, Valencia Villalvazo EY, Hernandez Rivera J, Ramirez Regalado B, Rojano Mejia D, Canto P: Analysis of polymorphisms and haplotypes in genes associated with vascular tone, hypertension and oxidative stress in mexican-mestizo women with severe preeclampsia. Clin Biochem 2013;46:627-632.

45 Gebhardt GS, Peters WH, Hillermann R, Odendaal HJ, Carelse-Tofa K, Raijmakers MT, Steegers EA: Maternal and fetal single nucleotide polymorphisms in the epoxide hydrolase and gluthatione s-transferase p1 genes are not associated with pre-eclampsia in the coloured population of the western cape, south africa. J Obstet Gynaecol 2004;24:866-872.

46 Canto P, Canto-Cetina T, Juarez-Velazquez R, Rosas-Vargas H, Rangel-Villalobos H, Canizales-Quinteros S, Velazquez-Wong AC, Villarreal-Molina MT, Fernandez G, Coral-Vazquez R: Methylenetetrahydrofolate reductase $\mathrm{c} 677 \mathrm{t}$ and glutathione s-transferase $\mathrm{p} 1 \mathrm{a} 313 \mathrm{~g}$ are associated with a reduced risk of preeclampsia in maya-mestizo women. Hypertens Res 2008;31:1015-1019.

47 Toppo S, Vanin S, Bosello V, Tosatto SC: Evolutionary and structural insights into the multifaceted glutathione peroxidase (gpx) superfamily. Antioxid Redox Signal 2008;10:1501-1514.

48 Margis R, Dunand C, Teixeira FK, Margis-Pinheiro M: Glutathione peroxidase family - an evolutionary overview. FEBS J 2008;275:3959-3970.

49 Hu YJ, Diamond AM: Role of glutathione peroxidase 1 in breast cancer: Loss of heterozygosity and allelic differences in the response to selenium. Cancer Res 2003;63:3347-3351.

50 Tang TS, Prior SL, Li KW, Ireland HA, Bain SC, Hurel SJ, Cooper JA, Humphries SE, Stephens JW: Association between the rs1050450 glutathione peroxidase-1 (c > t) gene variant and peripheral neuropathy in two independent samples of subjects with diabetes mellitus. Nutr Metab Cardiovasc Dis 2012;22:417-425. 